\title{
Load Sharing of Transformers for Intelligent Electric Power Management
}

\author{
${ }^{a}$ Fahad Khan, ${ }^{b, *}$ Ateeq Ur Rehman, ${ }^{c}$ Rao Muhammad Asif, ${ }^{d}$ Syed Rizwan Hassan, ${ }^{\text {e }}$ Muhammad \\ Tariq Sadiq, ${ }^{\mathrm{a}}$ Muhammad Arif, ${ }^{\mathrm{c}}$ Basit Ali Khan \\ ${ }^{\text {a }}$ Department of Electrical and Computer Engineering, COMSATS University Islamabad, Abbottabad Campus, Pakistan \\ ${ }^{\mathrm{b}}$ Department of Electrical Engineering, Government College University, Lahore, Pakistan \\ ${ }^{\mathrm{b}}$ College of Internet of Things Engineering, Hohai University, Changzhou 213022, China \\ ${ }^{\mathrm{c}}$ Faculty of Electrical Engineering, The Superior College (University Campus), Lahore, Pakistan \\ ${ }^{\mathrm{d}}$ Department of Electrical Engineering, NFC Institute of Engineering and Fertilizer Research, Faisalabad, Pakistan \\ ${ }^{\mathrm{e}}$ Department of Electrical Engineering, The University of Lahore, Pakistan \\ ${ }^{*}$ Corresponding Author Email: ateeq.rehman@gcu.edu.pk
}

\begin{abstract}
Power management has been one of the focused areas of research from the past few decades. Power blackout is the main problem nowadays and it occurs mainly due to outdated infrastructure used for electricity in industries. In a traditional grid, the consumer load information is obtained manually which is a time-consuming and expensive process. In this paper, a prototype is developed for the real-time off-site data monitoring and control of the consumer loads in the distribution network of the power grid. The designed prototype avoids the tripping of loads by the use of load sharing.
\end{abstract}

Keywords: Power management, Real-time data monitoring, Distribution network, Electricity blackout

Date Received 01-08-2019

Date Accepted 31-12-2019

Date Published 31-12-2019

\section{INTRODUCTION}

$\mathrm{I}_{\mathrm{o}}^{\mathrm{n}}$ ntelligent load management is one of the crucial requirements of future energy management systems, which provides electric consumers to better manage their loads and billings. Load management (LM) encourages distributed generation and optimizes the grid performance by controlling the electric loads.

LM controls the electricity consumption pattern and is applicable to both energy demand and supply sides. The supplyside LM characterizes the supplier planning to fulfill the demand needs whereas demand-side load management (DSLM) aims to influence consumers such that the shape of the load profile can produce optimal power. The DSLM primarily employs peak clipping and load shifting techniques. Technical, economic, and social measures are the main factors addressed by DSLM. The power load management techniques include the following:

- Peak clipping: It aims to reduce the loads at peak hours during specific periods of time.

- Valley filling: This technique involves building loads during off-peak hours.

- Load shifting: It combines the advantages of both peak clipping and valley filling where loads are shifted from peak to off-peak hours without altering the energy consumption.

One of the key advantages of LM is the elimination of running the power plants for peak demand hours and the associated challenges of the unexpected plant tripping [1]. Moreover, the $\mathrm{LM}$ lowers the $\mathrm{CO}_{2}$ emissions from these power

plants or backup generators. The private industry and public sectors are motivated to develop efficient LM technologies [3]. LM optimizes energy generation and distribution by reducing peak loads [2-5,7]. Peak demand hours typically occur in extreme weather conditions such as cold morning or evenings and hot evening when people arrive home from work and turn on their lights, heaters/air conditioners, and cook their evening meal. In rural areas, peak demands occur in summer months because of the large number of irrigation pumps connected to the electric network [2]. When the demand is increased, it is compulsory to manage the load properly, so different techniques are used to manage the load.

The monitoring of complex power system enables utility companies to manage their power resources. The traditional power system is being transformed with new technologies such as sensors, communications, and control. An intelligent management system takes necessary actions accordingly to the changes that occur in the power system. Therefore, the traditional power system needs to be changed and improvised with new smart technologies. These technologies provide constant information about the system regarding faults and power usage which decrease the manual work and optimize the system.

In this paper, an LM scheme is presented that can manage the load demands according to the grid capacity. The proposed work employs the parallel operation of transformers is done in this project. In this paper, our contributions include the following:

1. We have provided a brief overview of the conventional 
grid and the smart grid (SG).

2. The hardware implementation of LM in consumer premises is presented. The overloading of transformers is managed by the intelligent sharing of load with the other transformer. The design enables the uninterrupted power supply to consumers and provides an increased lifetime of the transformer by avoiding overloading and overheating.

3. ThingSpeak software is used that can provide real-time information about consumers' load.

\section{CONVENTIONAL GRID AND SMART GRID}

The traditional grid was developed around the 20th century $[8,12]$. A conventional grid is shown in Fig. 1 where electric power is generated, passes through power transformers and other essential steps are distributed to residential consumers. The multiple source generation by a solar, windmill, hydel, etc can also be employed for reducing transmission costs and power losses.

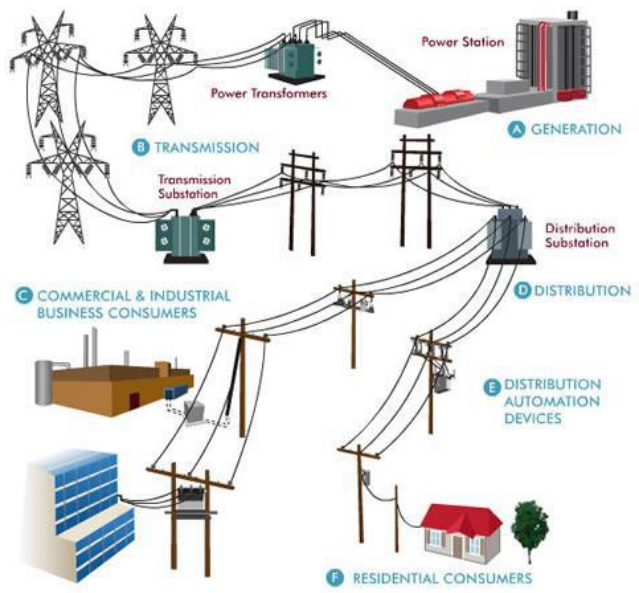

Fig. 1: Conventional Grid [11]

\section{A. Problems with Conventional Grid}

The traditional or existing electric grid is an outdated system with numerous problems. Few of the problems in tradition grid are the following:

1. The generation of power is centralized and it can only be distributed from the main plant to remote consumers causing high losses.

2. The traditional grid has an infrastructure that suffers failure, which leads to network congestion and power blackouts issues.

3. Due to a lack of monitoring, communications, and sensors deployments in the old grid, the repairs and restoration are manual, laborious, and time-consuming.

4. The existing grid is one of the major causes of $\mathrm{CO}_{2}$ emissions mainly due to the use of fossil fuels for power generation.

5. Electromechanical infrastructure and limited control severely affect the reliable performance of the traditional grid.

From the past few decades, efforts are being made to transform the traditional grid to a new and improved grid, which is called the smart grid (SG). The SG integrates communications technology, sensors, and control features into the power grid to increase grid reliability.

There are different perspectives regarding the SG is a new setup or an improvement in the traditional grid. Technically speaking, SG is a setup that has the following essential systems:

1. Smart infrastructure system for energy, communication, and information sharing.

2. Smart management system for control and management.

3. Smart protection systems for reliable operations, fault protection, and security-related services.

Power generation from renewable is one of the visions of SG [8]. The SG benefits both the utility and demand sides and provides a vast range of customer-oriented services [9]. Smart grid infrastructure is shown in Fig. 2.

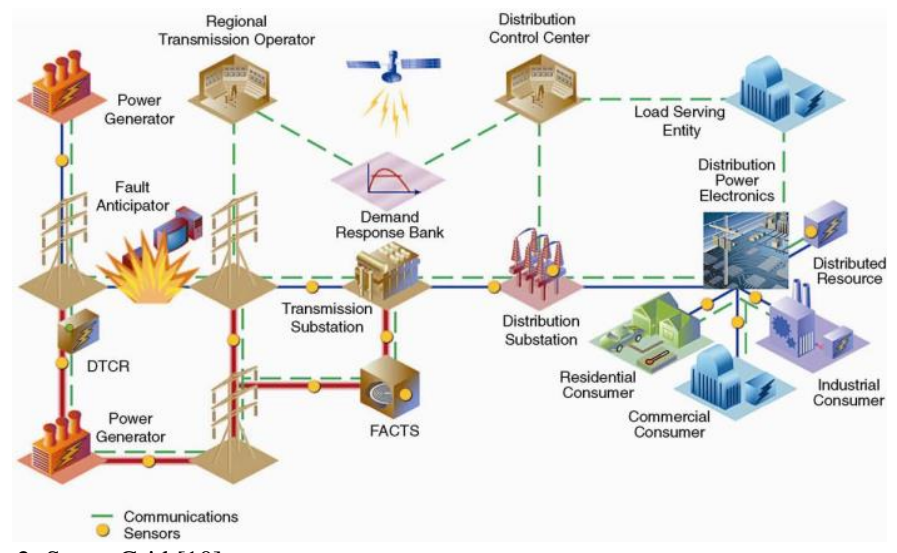

Fig. 2: Smart Grid [10]

$\mathrm{SG}$ is envisioned to provide reliable power distribution, supply and demand balance, flexibility in electric network topology, fault resilience, and security, etc [6, 8-10].

\section{PROPOSED SYSTEM}

The proposed load management system comprises of potential and current transformers, micro-controller unit, ESP8266 WiFi module, relays, and voltage regulation circuitry. The transformers can run loads at rated capacity. When loads at any of the two transformers exceed the rated value, the second transformer connected in parallel with the other will share the extra load with it.

The PIC16F877A microcontroller is used as the central processing unit for measuring the electrical quantities from the input signals at its ADC terminals. The real power consumption is obtained from the voltage and current is locally displayed at LCD and at the same time the information is transmitted through the ESP8266 module to the remote load monitoring center. The single line diagram of the proposed intelligent LM system is provided in Fig. 3 . 


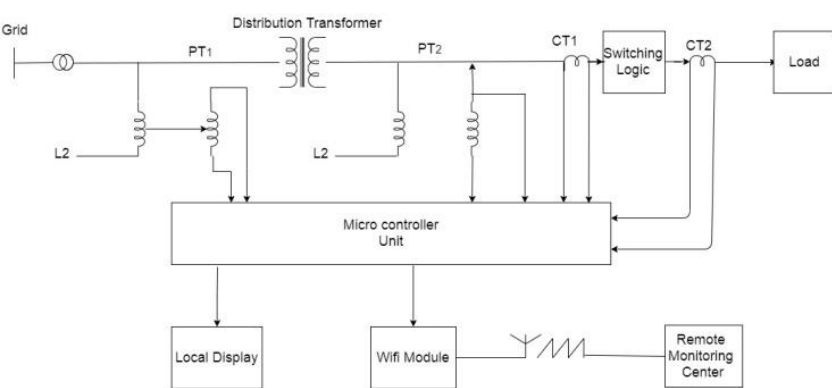

Fig. 3: Single-line Diagram of LM System.

Table 1 lists the component used in the implementation of an LM system through the load sharing of transformers.

TABLE I

Components Used in the Proposed System.

\begin{tabular}{|c|c|c|}
\hline S.No & Components & Quantity \\
\hline 1 & Power transformer & 2 \\
\hline 2 & Relay & 4 \\
\hline 3 & Current transformer & 2 \\
\hline 4 & Supply & 1 \\
\hline 5 & PIC16F877A Microcontroller & 1 \\
\hline 6 & ESP8266 module & 1 \\
\hline 7 & LCD & 1 \\
\hline 8 & Opto-coupler & 1 \\
\hline 9 & 7805 Regulator IC & 2 \\
\hline
\end{tabular}

\section{IMPLEMENTATION OF POWER LOAD MANAGEMENT SCHEME}

In the distributed electric power system, the load sharing of the transformer is performed between two transformers such that one transformer is connected in parallel with the other. Under normal load operating conditions, transformers run under the rated loads. However, when load demand is increased on any transformer, continuous power supply to the load is provided by sharing the additional load with the second transformer. This LM scheme, therefore, provides transformer protection from overloading and overheating. An overview of the proposed design is shown in Fig. 4.

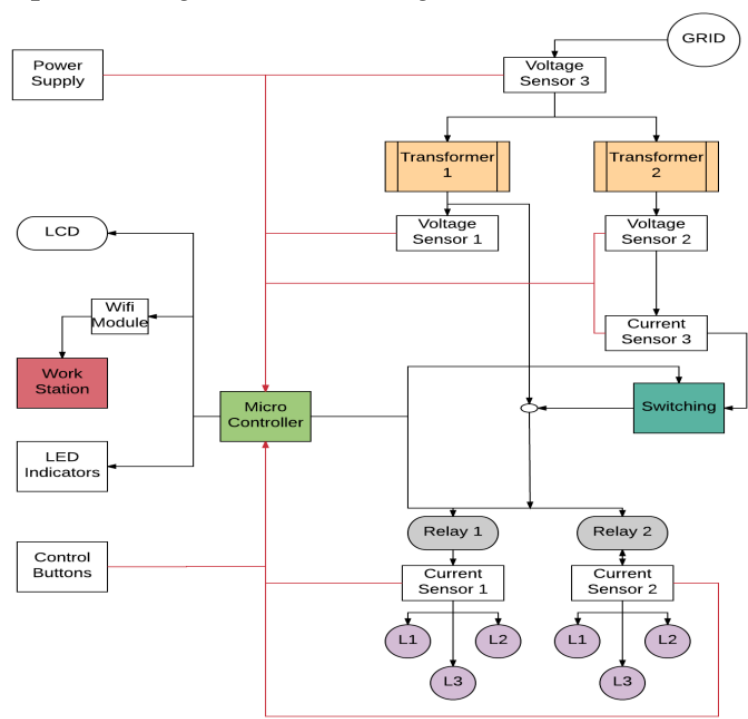

Fig. 4: Overview of the Proposed LM System.
The hardware of the LM system with two transformers and loads is shown in Fig. 5. Here three loads (bulbs) are connected to each transformer.

ThingSpeak is used as a software tool to get data at the remote center. ThingSpeak, which is an open-source IoT platform is used to store, analyze, and retrieve data from loads. The stored information enables utility companies and consumers to observe load data on gadgets and computers.

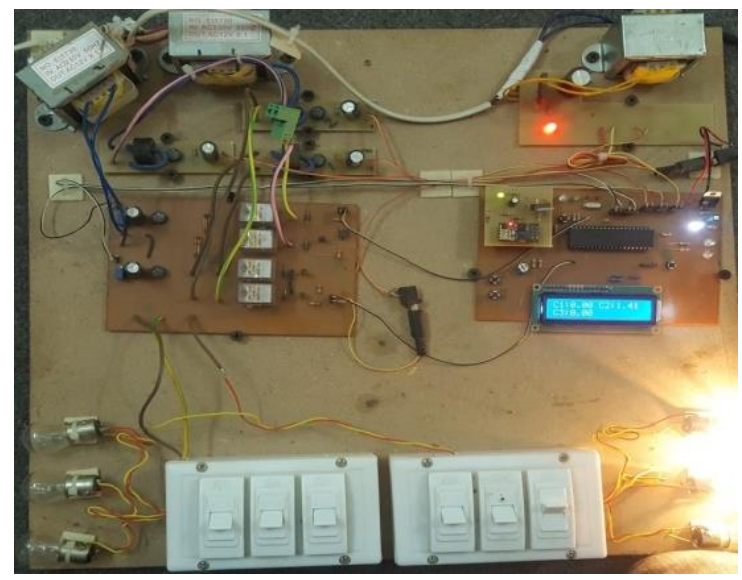

Fig. 5: Overview of the Proposed LM System.

\section{RESULTS AND DISCUSSION}

The hardware system is operated with different loads for its functionality and evaluation. Based on the load connected to the transformers, the results of the LM system are divided into the following three categories:

\section{Normal operating condition}

Each transformer has a rating of $2.1 \mathrm{~A}$. Note that transformer 1 is connected to consumer 1 and transformer 2 has consumer 2 loads. Under normal condition, transformer 1 has only two bulbs $\mathrm{ON}$ that draws a total of $1.4 \mathrm{~A}$, while transformer 2 has all loads OFF. There is no power-sharing between the transformers because no overloading occurs on the transformers. The hardware results are shown in Fig. 6.

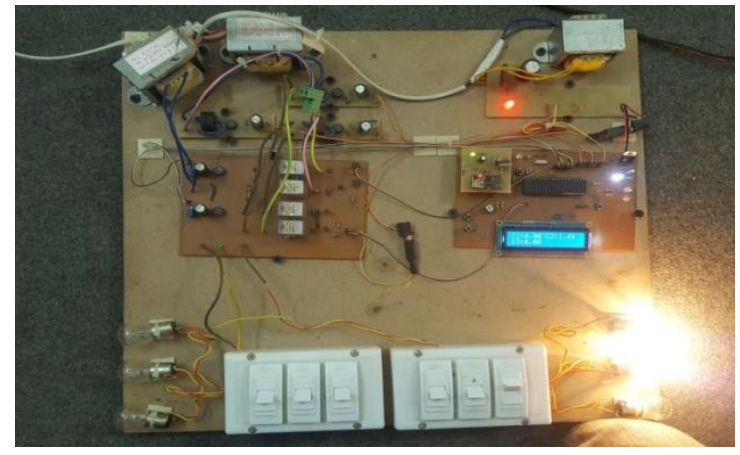

Fig. 6: Hardware Under Normal Condition.

In this case, as depicted in Fig. 4, the Green LED for powersharing is OFF. The current and output voltage of the transformer 1 and consumer 1 current and wattage consumption are shown in Fig. 7. 


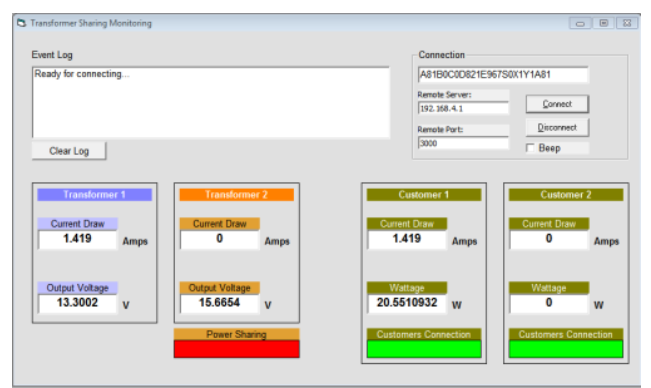

Fig. 7: Information for Normal Operation.

2. Power-sharing condition

In this scenario, two loads of consumer 1 are $\mathrm{ON}$ drawing 1.5 A. When the third load of consumer 1 is $\mathrm{ON}$, the rated value $\mathrm{o}$ transformer is exceeded and the transformer 2 will automatically share this extra load with it. The hardware results of power-sharing are shown in Fig. 8.

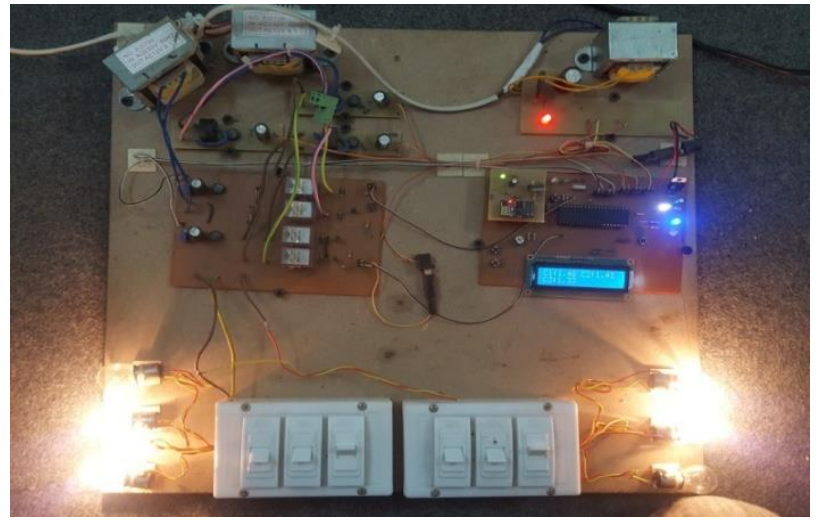

Fig. 8: Transformer and Load Information Under Power Sharing Condition

When both the transformers will share the load, then the Green LED for power-sharing will be turned ON as seen in Fig. 8. A message for transformer sharing in the event log will be shown in the software at the remote monitoring center. Fig. 9 shows the information for power-sharing at the remote center.

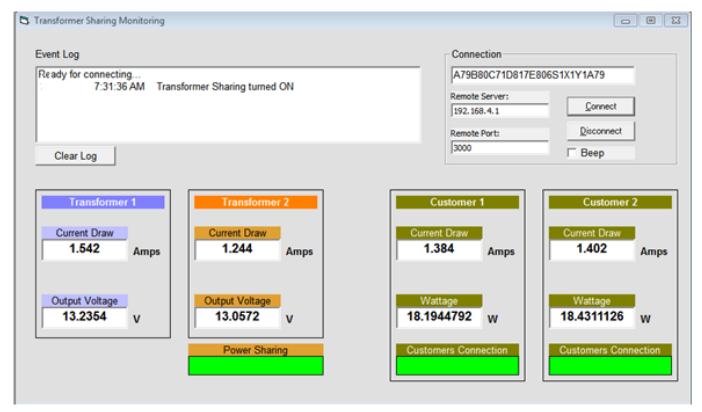

Fig. 9: Information for Power Sharing.

\section{Overloading Condition}

In this scenario, two loads of each of the consumers are turned $\mathrm{ON}$. The current drawn is $1.5 \mathrm{~A}$ for each consumer. If the third load of consumer 1 is ON then the total current drawn exceeds the rated value. Now the transformer 2 will automatically turn on and will share the load of the transformer 1 load. After that when the third load connected to either of the consumers then the value will exceed from the threshold value $(1.5 \mathrm{~A})$ for that consumer. The system will shut down that consumers load automatically and he will have to reconnect to the system. The hardware results of overloading are shown in Fig. 10.

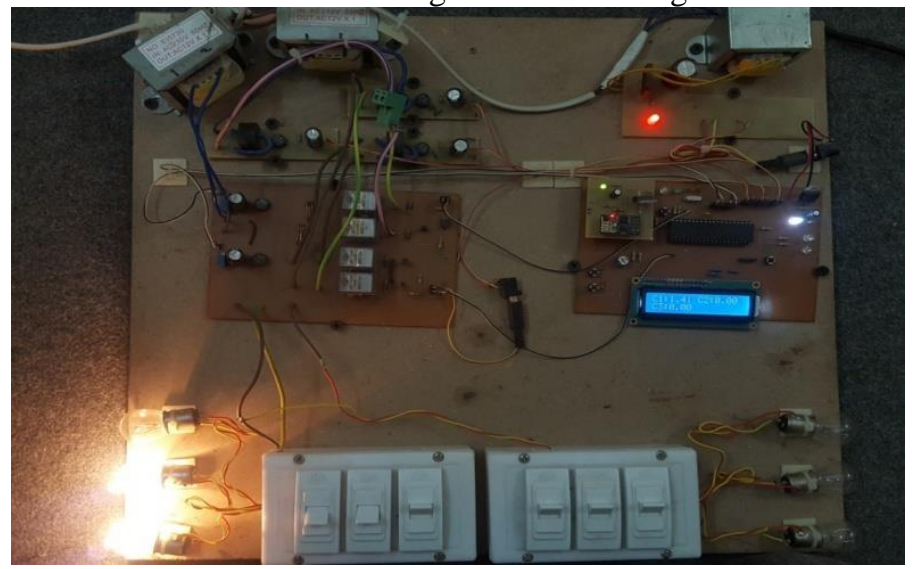

Fig. 10: Transformer and Load Information Under Overloading Condition

The information obtained at the remote station is depicted in Fig. 11.

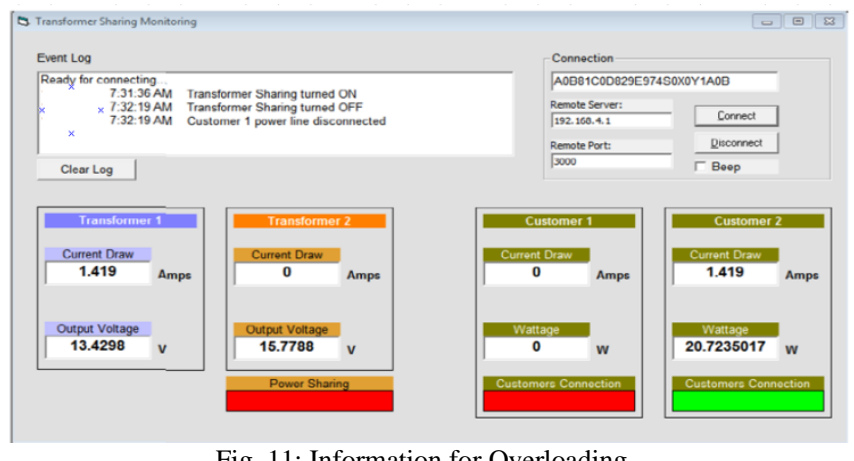

Fig. 11: Information for Overloading.

\section{CONCLUSION}

The conventional electric grid is experiencing a transformation process to a new setup of SG. One of the key systems in SG is the smart management system. In this work, an effort is made to monitor, control, and manage the power system with realtime customer data. The design provides protection of the transformer from overloading. The system performance is evaluated by running it under different scenarios.

\section{FUTURE WORK}

So far this project has been designed for off-site monitoring and control, but it can be extended to protect the equipment used in the distribution network. The extension of this project can be used to detect the theft of electric power at the distribution lines. This system can be implemented for the individual industrial consumer. This system is devised on a single-phase network; an extension of this system can be used for threephase systems. This system can be implemented on individual transformers networks as well as distribution substations. Implementing the system on all the distribution networks 
individually will help in achieving a smart distribution system across the country.

\section{REFERENCES}

[1] N. K. Suryadevara, S. C. Mukhopadhyay, S. D. T. Kelly and S. P. S. Gill, "WSN-Based Smart Sensors and Actuator for Power Management in Intelligent Buildings," in IEEE/ASME Transactions on Mechatronics, vol. 20, no. 2, pp. 564-571, April 2015.

[2] IlzeLaicane, DagnijaBlumberga, AndraBlumberga, and Marika Rosa "Reducing household electricity consumption through demand side management: the role of home appliance scheduling and peak load reduction" Energy Procedia, Vol. 72, pp: 222-229, June 2015.

[3] C. Alvarez, R. P. Malhame, A. Gabaldon, "A class of models for load management application and evaluation revisited", IEEE Transaction on Power Systems, Vol. 7, No. 4, pp. 1435, November 1992.

[4] M. R. Mcrae, R. M. Seheer and B. A. Smith, "Integrating Load Management Programs into Utility Operations and Planning with a Load Reduction Forecasting System," IEEE Trans., Vol PAS-104, No. 6, pp. 1321- 1325, June 1985.

[5] C. W. Gellings, A. C. Johnson and P. Yatcko, "Load Management Assessment Methodology at PSE\&G", IEEE Trans.,Vol. PAS-101, No. 9, pp. 3349-3355, September 1982.

[6] S. Bu, F. R. Yu, P. X. Liu, and P. Zhang. Distributed scheduling in smart grid communications with dynamic power demands and intermittent renewable energy resources. IEEE ICC'11 Workshop on Smart Grid Communications, 2011.

[7] Y. M. Atwa, E. F. El-Saadany, M. M. A. Salama, and R. Seethapathy. "Optimal renewable resources mix for distribution system energy loss minimization," IEEE Transactions Power System, 25(1), pp:360-370, 2010.

[8] A. Monti and F. Ponci, "Power Grids of the Future: Why Smart Means Complex," 2010 Complexity in Engineering, Rome, 2010, pp. 7-11. doi: 10.1109/COMPENG.2010.44

[9] Hart, D.G. "Using AMI to realize the smart grid, Power and Energy Society General Meeting-Conversion and Delivery of Electrical Energy in the 21st Century at Pittsburgh in Pennsylvania_USA, 2008.

[10] V. C. Gungor, D. Sahin, T. Kocak, C. Buccella, C. Cecati, and G. P. Hancke, "Smart grid technologies: communication technologies and standards," IEEE Transactions on Industrial Informatics, vol. 7, no.14, pp.529-539, 2011.

[11] T. L. Vandoorn, B. Meersman, J. D. M. De Kooning and L. Vandevelde, "Analogy Between Conventional Grid Control and Islanded Microgrid Control Based on a Global DC-Link Voltage Droop," in IEEE Transactions on Power Delivery, vol. 27, no. 3, pp. 1405-1414, July 2012.

[12] A. Hassan, A. U. Rehman, N. Shabbir, S. R. Hassan, M. T. Sadiq, and J. Arshad, "Impact of Inertial Response for the Variable Speed Wind Turbine," 2019 International Conference on Engineering and Emerging Technologies (ICEET), Lahore, Pakistan, 2019, pp. 1-6. 